\title{
Les trois fils de rois, édité par Giovanni Palumbo
}

\section{Maria Colombo Timelli}

\section{(2) OpenEdition}

\section{Journals}

\section{Édition électronique}

URL : http://journals.openedition.org/studifrancesi/32833

DOI : 10.4000/studifrancesi.32833

ISSN : 2427-5856

\section{Éditeur}

Rosenberg \& Sellier

\section{Édition imprimée}

Date de publication : 1 décembre 2005

Pagination : 616-617

ISSN : 0039-2944

\section{Référence électronique}

Maria Colombo Timelli, «Les trois fils de rois, édité par Giovanni Palumbo », Studi Francesi [En ligne], 147 (XLX | III) | 2005, mis en ligne le 30 novembre 2015, consulté le 20 avril 2021. URL : http:// journals.openedition.org/studifrancesi/32833; DOI : https://doi.org/10.4000/studifrancesi.32833

\section{Ce document a été généré automatiquement le 20 avril 2021.}

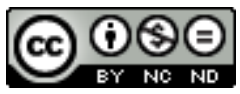

Studi Francesi è distribuita con Licenza Creative Commons Attribuzione - Non commerciale - Non opere derivate 4.0 Internazionale. 


\title{
Les trois fils de rois, édité par Giovanni Palumbo
}

\author{
Maria Colombo Timelli
}

\section{RÉFÉRENCE}

Les trois fils de rois, édité par Giovanni PALUMBO, Paris, Honoré Champion, 2002, 635 pp.

Les trois fils de rois, long récit en prose «d'armes et d'amours» connu aussi sous le titre Istoire royale, est transmis par sept manuscrits $d u \mathrm{XV}^{\mathrm{e}}$ siècle, onze imprimés du XVI ${ }^{\mathrm{e}}$ (1501-1579), et une traduction en moyen anglais encore du XVe . A cette riche tradition, témoignage d'un succès que le passage à l'édition imprimée ne démentit pas, il faut encore ajouter un manuscrit perdu (le n. 1292 du catalogue de Barrois), et surtout un huitième manuscrit, que Giovanni Palumbo a retrouvé à la British Library lorsque son édition était déjà en cours d'impression (il s'agit du ms. Harley 4408, auquel l'éditeur a consacré un long article, paru dans «Medioevo Romanzo»: cfr. questi «Studi», CXLIII, 2004 , p. 340 ). Les témoins des trois fils de rois se répartissent en deux familles correspondant de fait à deux rédactions distinctes (exception faite pour le ms. $H$, qui contamine les deux), que l'on peut désigner respectivement comme «version Créquy» (famille b) et «version Philippe le Bon» (famille a) (cf. l'Introduction, p. 25, et le stemma, p. 36). Giovanni Palumbo montre, de façon convaincante, que la version a est plus proche du texte original, alors que la version b représente un remaniement: le ms. $A$, appartenant à cette famille, sert de base à l'édition critique. Ce choix se justifie autant par la qualité du texte de $A$ que par la mauvaise qualité du seul manuscrit éventuellement utilisable de la famille b (le ms. B, défiguré par de nombreuses erreurs). C'est sans doute à David Aubert lui-même, célèbre «excripvain» du Grand Duc dont le rôle de copiste se double et se complète de celui de remanieur, que l'on doit les innovations du manuscrit $A$, et notamment l'ajout du Prologue et la répartition de la matière en 42 chapitres, avec insertion des rubriques, caractéristiques qui se retrouvent très régulièrement dans les manuscrits de la même famille. L'Introduction de Giovanni Palumbo rend aussi compte de certaines particularités linguistiques de ce 
manuscrit, qui présente de rares traits nord-orientaux et picards. Suivent l'analyse du texte (le sujet reprend certains thèmes et motifs, entre autres folkloriques, bien connus), la justification du titre retenu, et une étude littéraire, synthétique mais rigoureuse. L'éditeur peut dater approximativement la composition entre 1454 et 1463 , et montre le grand intérêt de cette prose originale, récit pseudo-historique dont l'auteur s'efforce d'éviter toute invraisemblance par la suppression des éléments merveilleux. Sa recherche d'effets de réalisme se lit aussi dans la représentation du temps et de l'espace (avec une chronologie apparemment précise, et un cadre géographique bien réel) et dans le choix des noms des protagonistes, qui rappellent, dans la quasi totalité, de grands personnages de la cour bourguignonne de la moitié du $\mathrm{XV}^{\mathrm{e}}$ siècle. Le résultat est une œuvre récréative, mais surtout un roman de propagande politique, à visée didactique, qui réunit des éléments romanesques, épiques et historiques, capables tous de susciter l'intérêt de Philippe le Bon: on rappellera surtout le motif portant de la lutte contre les Turcs, qui traverse le récit dans sa totalité, et l'épisode du banquet du paon (chapitre 26), dont les liens avec le célèbre banquet de Lille sont frappants.

2 L'édition du texte est remarquable (elle occupe les pp. 81-448). Elle est accompagnée d'une série d'apparats rendant compte de la complexité de la tradition et de la richesse du récit: la liste des corrections apportées au manuscrit de base (pp. 449-454), celle des variantes (très nombreuses, malgré la sélection opérée, justifiée dans l'Introduction, $p$. 44: pp. 455-599). Les notes au texte (commentaires linguistiques, stylistiques, philologiques, plus rarement notes sur le contenu) occupent encore les pp. 601-610. Suivent l'Index des noms propres (pp. 611-614) et le Glossaire, nécessairement sélectif, mais comprenant les renvois au texte, qui se révèle utile et bien fait (pp. 615-630); quant à la Table des proverbes et expressions proverbiales, on pourrait ajouter quelques expressions: pour s'en tenir aux tout premiers chapitres, cf. 2.57 («les choses mondaines n'ont point de durée, mais le royaulme du ciel n'a point de fin»), 3.38 («car contre le plaisir de Nostre Seigneur tout est impossible»), 4.120 («tousjours les rapporteurs y mettent voulentiers aucune chose du leur»).

On ne peut que féliciter Giovanni Palumbo d'avoir mené à bien ce travail d'édition, en lui suggérant peut-être une ultérieure étude comparative, afin de mettre en relief, plutôt que les traits caractéristiques de cet auteur si attachant que s'est révélé David Aubert grâce notamment aux études récentes de Richard Straub (D.A., clerc et escripvain, Atlanta-Amsterdam, Rodopi, 1995) et aux contributions réunies par Danielle Quéruel (Les manuscrits de D.A., "escripvain» bourguignon, Paris, PUPS, 1999), les caractères de la version «originale». Certainement due à un auteur de moindre valeur littéraire, elle me semble pourtant mériter un travail d'ensemble et une certaine attention. 